\title{
Special Section Editorial: Toward a Geographical Software Studies
}

\section{Introduction}

Geographic concepts have always been implicated in calls to study software as a political, cultural, or social phenomena, even if they have not always been named as such. "Software structures and makes possible much of the contemporary world" writes Matthew Fuller in the introduction to Software studies: a lexicon ${ }^{1}$ - a succinct summary of the central problem guiding software studies, gesturing towards the spatial implications of software. So too in the insistence on the materiality of software do we find software studies bringing forth software as material thing that exists in and through space, in sites and scales as diverse as voltage differences in circuits, nation states, digital maps, and networks of computers. As geographic theory has long insisted, space is not just a container for software, but is actively produced by software in its various material, situated, and socio-technical contexts. Influenced in part by the exciting work that has developed in software studies in addition to geography's own rich history of engagement with technology, a growing number of geographers have turned to software as an object of study, producing theories and methods to understand the relationship between computation and space.

This special section emerged from our effort to bring together a group of scholars working on geographical approaches to software studies at the Annual Meeting of the American Association of Geographers (AAG) in 2016. Spanning four sessions, presenters expressed a variety of orientations towards software, with diverse theoretical and methodological approaches to understanding how software has come to structure the world. This introduction is a brief summary of some of those approaches, but more importantly, it suggests some of the ways that software studies and geography might productively learn from and build upon each other. These crossdisciplinary discussions are important as we come to terms with the growing power of software in our everyday lives and attempt to build critical practices that not only study, but also build other ways of knowing the world through computation. Ultimately, we frame the discussions that follow in ways we hope will encourage software studies scholars to grapple with the spatial implications of software.

\section{Reflections on past engagements with computation}

Within geography, recent engagements with software build upon a history of sometimes contentious, but ultimately productive debates that readied the discipline for critical orientations toward software and computation. The introduction of computational systems to the discipline in the 1950s and 60s was driven by interest in quantitative analyses and epistemologies, in what is known as the "quantitative revolution."2 For some geographers, computing promised a more 'scientific' geography that could produce concrete laws of social and spatial phenomena. ${ }^{3}$ While the take up of quantitative methods was fraught and uneven, the quantitative revolution produced a generation of geographers who engaged deeply with mathematical, statistical, and computational approach to geographic problems.

In the 1970s and 80s, however, many geographers argued that quantitative approaches frame social process as overly rational, divorced from power relations, and unable to ascribe meaning to the patterns they analyzed. ${ }^{4}$ These critiques from human geographers drew on bodies of research as diverse as Marxism, feminism, and post-structuralis ${ }^{5}$. Seeking to identify and understand the inner workings of social and political contingency, power, and stratification, many human geographers shunned the methods of quantitative geography, even if they were themselves products of, and influenced by their academic roots in, the quantitative revolution. And so the pendulum swung away from quantification and computation as human geographers embraced qualitative and humanistic ways of understanding space, positing this new direction as diametrically opposed to what had come before.

In spite of these new research directions, the quantitative moment would leave a lasting mark on the discipline, sometimes leading to knee-jerk reactions against quantitative approaches, but more positively, leading some scholars to develop complex, critical approaches that engage with and use quantitative methods. ${ }^{6}$ We might draw parallels between reactions to the quantitative moment in the discipline and more recent excitement around the possibilities for 'big data' research, which perhaps has led current geographic research to be more cautious and critical in engaging with data-driven research. ${ }^{7}$ Theoretical and methodological shifts in the discipline weigh heavily on the present as the grandiose claims of the quantitative revolution still haunt geography today.

With the growing popularity of geographic information systems (GIS) in the 1990s, human geography would again publicly grapple with the place of computers and quantification in the discipline. GIS, in the eyes of its critics, was a diversion from important philosophical innovations in spatial thought, signaling a regression in epistemological developments and producing spatial representations that merely reflected the "concrete material and ideological needs and interests" of the powerful. ${ }^{8}$ That is to say, criticisms leveled against GIS often claimed it was a form of "naïve empiricism" that hearkened back to the quantitative revolution. ${ }^{9}$ In a period that Nadine Schuurman ${ }^{10}$ classifies into three waves, antagonisms between critical human geographers and GIS specialists were at first focused on this purported resurgence of positivism in GIS practice; the second wave consisted of more subdued tensions between the two; and the third saw critical human geographers increasingly familiarizing themselves with the languages, practices, and affordances of GIS software.

Out of the second and third waves stemmed the research program of "critical GIS," which has contributed insights into the social, political, and epistemological dimensions of spatial technologies, data, and software ${ }^{11}$, often while using GIS as a research tool. ${ }^{12}$ Many of these insights have carried over into recent theoretical and practical applications of volunteered geographic information, spatial Big Data, spatial media, and software. ${ }^{13}$ In the wake of debates around the quantitative revolution and GIS, it is not uncommon today for geographers to use, produce, and critically engage with software in productive synthesis during the course of their research. In recent years, especially fruitful areas have included those integrating qualitative research data and methods into $\mathrm{GIS}^{14}$, new Javascript libraries and software for web-based visualizations ${ }^{15}$, and the nascent growth of the digital (geo)humanities. ${ }^{16}$

Beginning in the 90s, geographers also began building on ideas from geographic thought, science and technology studies, and other debates and applying them in innovative ways to understand technologically-mediated and technologically-produced spaces and socialities. Scott Kirsch, for example, draws from theories of uneven development to show how, as some spaces are brought very close together through new technologies, new technological spaces form in the interstices, often becoming further isolated ${ }^{17}$-an argument that mirrors Doreen Massey's work on power-geometry. ${ }^{18} \mathrm{He}$ argues that, on one hand, technology produces "a set of structural relations," while on the other hand he argues for a, "return to the surface of experience to understand how the geographies of everyday life are increasingly mediated." Thrift and French describe a similar movement, as software constitutes both a technological unconscious through which we see the world and a structure that is able to standardize and classify urban space, leading to what they call the 'automatic production of space.'19 
So on one hand, we find accounts of how geographical spaces are remade by computing. On the other hand, we find accounts of how software changes how we come to know and theorize space. As Dourish and Bell remark, "we want to draw attention to the ways in which, in turn, the embedding of a range of infrastructures into everyday space shapes our experience of that space and provides a framework through which our encounters with space take on meaning." 20 Or, as Shannon Mattern observes in her study of the history of the urban dashboard, the screen becomes an "epistemological and methodological pastiche" as things that are not able to be represented are left out. ${ }^{21}$ For Mattern, this means that the dashboard "embodies a kind of ontology: it defines what the city is and isn't." In other words, there are only particular things that can become knowable through the algorithmic methods that subtend the urban dashboard, so only particular understandings of the spaces of the city become legible and actionable. In this special section, as well as in many geographic approaches to studying software, we find scholars moving between an understanding of software as something integral to shaping our geographical imaginations ${ }^{22}$ while simultaneously structuring the spaces of everyday life.

\section{Toward a geographical software studies}

Kitchin and Dodge, in an attempt to bridge geography and software studies, describe the ways that software code can be made to produce spaces - that is, set and enforce parameters around how space may be engaged and embed within the landscape social and cultural signifiers. ${ }^{23}$ In debates that surrounded this argumentation, geographers have argued that in contemporary cities, spaces cannot be separated from their entanglements with code, algorithms, sensors, and data. Space and the digital are mutually constitutive - it is through space that technologies are imagined, deployed, and unevenly implicated, and space itself is produced through these processes. These ideas have been applied to airports, securitized urban spaces, and even consumption patterns in cities. ${ }^{24}$ We can further see this in processes of software-sorting that produce spatial inequality ${ }^{25}$, in the need for mobile computing to overcome limits to mobility $^{26}$, in the exploitation of physical resources on which computing depends ${ }^{27}$, and in the production of spaces of data centers, cables, and satellites. ${ }^{28}$

With the growing interest in researching the geographic implications of computation, some geographers have recently begun to investigate software at the level of the algorithm. ${ }^{29}$ While computational processes were often central to geographic accounts of software, the move towards explicitly flagging algorithms as objects of study is a promising development for geography, which has much to learn from the work that has been done in software studies. In this nascent body of work, geographers are questioning the ways algorithms, often embedded directly into the urban fabric, produce spaces for the purposes of capital accumulation, social and political control, the production of social meaning, and relations of power. ${ }^{30}$

In the last few years, geographers have developed rich resources to intimate the contours of a revitalized, truly interdisciplinary geographical software studies. We envision our contribution less as charting out a fundamentally new field, and instead as building connections between ongoing work of geographers and software studies scholars. In the rest of this section, we highlight what we see as two potentially promising areas for future research directions: the taking up of the philosophy of Gilbert Simondon, and digital humanitarianism.

\section{Simondon and Stiegler, transduction and technics}

First, we underscore the recent engagements with the concept of transduction, which has its roots in Simondon's thought, as it applies to spatial phenomena. ${ }^{31}$ Geographers have begun to read the relationship between space and digital media through the ways in which the latter brings new spaces into being. In these accounts, software embedded within the spaces of everyday life constantly modulates material and social relations. This means that space is always being remade through automated computational processes as they interact with material processes and non/human agency, with unpredictable results. In fact, in this conceptualization of space, humans, non-humans, technology, and geographies are all intricately interwoven and mutually individuated - that is to say, it is through technology that members of collectives form individual identities through space. ${ }^{32}$ Importantly, such an approach necessitates interrogating the technology itself as a mediating actor to non/human experience and knowledge; software does not simply "capture" human intentionality, but instead works to direct individuals, promote epistemological closure, and convey norms and values. ${ }^{33}$ In his ontology of technology, Simondon shows that the technical object - say, a module of code, or a user interface - itself can be read as an aesthetic artifact similar to a work of art or a literary composition. These technical objects rewrite space and spatial relations, bringing some into being, enclosing others, and foreclosing yet others.

Linkages between technics and individuation are critical for the work of Bernard Stiegler, who is himself indebted to Simondon. ${ }^{34}$ For Stiegler,technics - technical objects and their uses - are means through which time and space is ordered and produced. ${ }^{35}$ Importantly, technics serve as retentionary devices, or ways of perceiving and remembering environments across physical places, relational spaces, temporally distanciated moments, and even generations. Borrowing from Simondon the notion that individuals (re)form their subjective consciousness in relation to the collective, Stiegler contends that this process of individuation occurs through technics. That is to say, technics are to be understood as retentionary devices through which individual and collective identities, ideas, and spatialities are formed. Technics thus are agents in the social production of space-time. By extension, technics are themselves cultural artifacts that, when interrogated, lend insights into these socio-spatial process.

\section{Digital humanitarianism}

Digital humanitarianism is an emerging body of research that contrasts with the work of Simondon and Stiegler yet which suggests new productive theoretical trajectories. The last two decades of technological transformations within humanitarianism have produced new sources of labor, data, epistemologies, and implements that all effectively shape human interactions with the world and specifically with humanitarian crises. This new set of social-relational, technological, and spatial relations are collectively called digital humanitarianism. Digital humanitarianism is comprised of crowdsourced labor mediated through web-enabled software, like the Javascript-based digital spatial data editor iD for the crowdsourced global basemap OpenStreetMap. Through the iD software interface, users drag roads, draw buildings, and so on, creating data visually rendered by the Javascript library D3.js. Digital humanitarians also produce software to collect and analyze big data such as social media and urban Internet-of-things sensors; popular platforms for doing so include Nextdoor, Tweak the Tweet, Hootsuite, and more traditional large dataset analysis approaches such as those produced by the GeoVista Center at Pennsylvania State University. Describing digital humanitarianism's promise, one prominent author wrote, "today's human networks and live maps are changing the world" and later, also referring to digital humanitarianism, that "Big Data is changing the face of humanitarian 
response". 36

Leaving such boosterist claims aside, a growing collection of research is interrogating the epistemological and socio-spatial implications of digital humanitarianism. For one, Burns describes how digital humanitarian software provides a conduit for producing some knowledges about humanitarian crises while structurally omitting other knowledge. ${ }^{37}$ For example, the popular Ushahidi interface establishes a categorization scheme that delimits the sorts of knowledges produce-able in each deployment. As well, the Humanitarian OpenStreetMap Team's shared data model is often a point of contention in the ways it acknowledges only relatively stable visual phenomena rather than a range of affective, intergenerational, and intuitive knowledges of spatial objects. Givoni argues that digital humanitarian software and platforms implicate the forms of participation and democratic engagement that emerge in crises: "What is distinctive about the novel conceptualizations of publics that crisis mappers seem to fit so well is the emphasis they put on the effective devices, platforms, concerns, and discourses upon which the existence of the public as an aggregate of strangers depends." 38 Likewise, Duffield observes that digital humanitarian software enables action from a distance, negating its affirmatory promises in the disbalanced spatial politics that emerge. ${ }^{39}$ These complexities entangle new forms of software-based political economies, as they are often seen as innovations that rework neoliberal governance for socio-technical contexts. ${ }^{40}$

\section{Software studies session at the AAG}

This special section on a geographical software studies emerges from a series of four sessions at the 2016 annual meeting of the American Association of Geographers. The series included three sessions of papers, in which authors presented a prepared talk, and an open-ended panel in which six panelists provoked an audience-engaging conversation around software and space. The conversations that transpired there have informed our account above. Here, we briefly describe the breadth of work represented in those sessions, and synthesize common and recurring themes. We do this both in order to demonstrate the range of approaches toward geographical software studies, and to contextualize the three papers within this special section.

The first of the paper sessions focused on new algorithmic, protocological, and political-economic infrastructures. These infrastructures are at times comprised of code and software design itself, and at other times software plays a key role in larger socio-technical assemblages. For presenter Ashwin Jacob Mathew, Internet protocols - the sets of instructions guiding transmission of digital information via networked devices - should itself be understood as the manifestation of spatial practices. Protocol stabilizes and orders seemingly "place-less" digital activities into physical infrastructures such as cables, Domain Name Servers (DNS), and home routers, which are themselves unevenly distributed and have emerged from particular political and militaristic contexts. Extending Galloway's foundational work on protocol, Mathew argues that it is through these mechanisms that protocol becomes an important site for geographers to interrogate. Similar concerns motivated Till Straube's investigation into the materialist politics involved in the stack ${ }^{41}-$ the infrastructure of data models, transmission technologies, governmental structures, and lines of software code that make up a technological system. ${ }^{42}$ For Straube, the softwares comprising data infrastructures exhibit epistemological propensities, reifying the placeless observer. He argues that the stack requires a topological reading that unpacks the spatial, historic, ontological, and epistemological contexts that are readable in the stack's constituent technologies. Laura Beltz-Imaoka likewise critiqued software infrastructures, looking at the predominant GIS company Esri's discursive shift from producers of software packages to software platforms $s^{43}$. This shift signals new ways late capitalism responds to social-discursive values that prioritize newness, entrepreneurialism, and post-Fordist customizability.

The second paper session, themed around issues of language and emerging research tools, questioned the ways discourses, ideologies, norms, and values come to be encoded within software. In this session, Matthias Plennart looked at the historic development of the OpenStreetMap (OSM) software, as it pertains to the collection and production of volunteered geographic information ${ }^{44}$. As OSM asks laypeople to produce spatial data, its data model, technical affordances, and socio-cultural self-justification all frame the types of knowledge and types of phenomena that can gain legitimacy through visibility ${ }^{45}$. For Plennart, this means geographers should pay particular attention to the historic junctures where the software took one direction rather than others, and that juncture's implications for participation, knowledge politics, and geographical imaginations. Luke Bergmann was equally attuned to the ways in which geographic representations influence the sorts of questions researchers ask, and thus the kinds of knowledge scholars produce ${ }^{46}$. Proposing a rethinking of GIS from Geographic Information Systems to Geographical/magination Systems, Bergmann articulated a new vision for geographic computation that draws on post-Newtonian, non-Euclidean relational spaces ${ }^{47}$. This vision would move from a conceptualization of space as a container to an active agent in the production of subjects and of phenomena. His collaborative project with Nick Lally, called Enfolding, is a software tool that enables the creation and visualization of these complex spaces.

Our next session tackled the connections between visuality and control. While geographic research has a long history of questioning surveillant technologies, including cartographic products, this set of papers sought theoretical and empirical clarity on emerging modes of "seeing" the city. Craig Dalton reported on a qualitative study that questioned the structures of social and political forces framing Google Maps users' wayfinding practices ${ }^{48}$. Dalton notes that Google's business model, focused on ad-driven revenue generation, influences the ways people get navigation information and even the ways they interact with their environments. Aaron Shapiro also critiqued a Google product, drawing connections between broken windows policing strategies and Google Streetview's urban epistemologies ${ }^{49}$. Streetview's processes of creating information from visual artifacts informs users of the phenomena that should be important for them and the kinds of urban spaces citizens should visit or avoid; the ultimate implication of this "informaticization" is disproportionately negative impacts on marginalized communities. These communities served for a focal point of Teresa Scassa's research into crime mapping, where particular values and norms come to be concretized in the discourse of "crime" while others go unnoticed ${ }^{50}$. Maps of the locations and distributions of these crimes communicate and publicly reiterate narratives of control, power, well-being, and police transparency. Mapping software, in this particular use, factors into both how people come to know neighborhoods in their city, and how systems of control are reproduced.

Our last session consisted of a loosely-structured panel discussion interacting with the audience. The panelists included Monica Degen ${ }^{51}$, Keith Woodward ${ }^{52}$, Elvin Wyly ${ }^{53}$, Pip Thornton ${ }^{54}$, Daniel Cockayne ${ }^{55}$, and Matthew W. Wilson ${ }^{56}$. This conversation, rather than presenting new research outcomes, focused on synthesizing ideas across the sessions. Panelists and audience members grappled with what's new here: are we observing the re-emergence of old socio-political spatial relations, or does software indeed move us in new directions? What is the particular agency we ascribe to software, and how does software analytically figure into larger sociotechnical assemblages? What roles does contingency have in these debates, which typically presuppose closure, determinacy, and predictability? The panelists noted the variety of interests covered in the research presentations - state-based forms of power, capital accumulation, knowledge legitimacy, and political struggle - and asked whether software is a sufficiently cohesive lens through which 
these interests can be elucidated. While space was well-covered, other less-pervasive geographic concepts included place, landscape, representational space ${ }^{57}$, power-geometries ${ }^{58}$, and transduced space.

The panel's objective was not to answer these questions, but instead to think about the implications of them, and offer reflections on how the paper presentations push forward new research agenda-setting questions. Accordingly, we think of the questions above as pressing questions confronting the field, as parts of what might be considered a disciplinary research agenda.

\section{Summaries}

Three of the papers from the AAG sessions are presented in longer form in this special section. They represent three cuts on the spatial implications of software, giving insight into how software studies might engage with geographical concerns.

In a careful study of neighborhood location software, Will Payne shows how different software packages construct and communicate neighborhood names and boundaries. Through an analysis and comparison of the computational decisions that underlie these processes, the article shows how these decisions shape an understanding of the spaces of the city. The resultant spatial imaginaries mediate how people navigate, interact with, and produce space, echoing the dual movement of software producing space and producing differential understandings of space. The article concludes with possible alternatives for digital representations of the city, suggesting ways forward informed by the careful study of existing software systems.

If software shapes understandings of cities and neighborhoods, so too does it shape understandings of language. Warren Sack's article, extending Foucault, argues that we are entering a "computational episteme" in which language is being torn from its geographical context and shaped by computational understandings of distance. Instead of being rooted in nation-building territorial projects, interrupted by borders, and modulated through face-to-face communication, computation allows language to break free from many of its geographical limits. In its place, companies like Google create new understandings of distance and proximity based on algorithmic functions aimed at producing profit for the company.

Similar themes weave through Pip Thornton's exploration of (con)text - the ways in which words are imbued with meaning, agency, and social relationality. The algorithms and models of linguistic space always point to other words and signifiers, rather than to semantics, connotation, or contradiction per se. Doing so can have consequences that are often humorous - as when in the Ukrainian language Google mistranslated "Russia" as "Mordor" - but are always indicative of deeper, more concerning processes of control, capital accumulation, and patriarchy. Using thinkers as diverse as de Certeau and Derrida, Thornton refines the concept of language as space in digital milieu, giving us tools to understand the spatial-relationalities produced in search engines, automatic translations, and digital ads. More specifically, the concept of distance, differently articulated across platforms, becomes central to understanding the production of these spaces. With Google and other corporations' increasing mediation of language, submitting linguistic algorithms to such critical scrutiny is becoming increasingly important.

\section{Conclusion}

Geography has long struggled with the place of computers within the discipline, from the punch card systems of the quantitative revolution in the 1950 s and 60s that promised to mathematically model the world ${ }^{59}$ to the GIS wars of the 90 s when scholars battled over the politics of computational representations of space ${ }^{60}$. Those early lessons warned geographers of the dangers of buying into the snake oil claims surrounding computational systems that promised to transform the discipline. The GIS wars that followed taught geographers to be wary of hard claims to objectivity (as viewed from nowhere) that the machines promised for so many. What emerged is a discipline of scholars that, at their best, use and build software for various research functions without forgetting that software is just another way of seeing the world. It is in this synthesis of creation, use, and criticality that we find the promise of a geographical software studies that can productively grapple with the spatial implications of software without posing software as either a savior or bogeyman.

1. Matthew Fuller, ed., Software Studies: A Lexicon, Leonardo Books (Cambridge, Mass: MIT Press, 2008).

2. Trevor J. Barnes, "Retheorizing Economic Geography: From the Quantitative Revolution to the 'Cultural Turn'." Annals of the Association of American Geographers 91, no. 3 (2001): 546-565; lan Burton, "The Quantitative Revolution and Theoretical Geography". Canadian Geographer, 2, no. 4 (1963): 151-162.

3. Trevor J. Barnes, "Placing Ideas: Genius Loci, Heterotopia and Geography's Quantitative Revolution," Progress in Human Geography 28, no. 5 (2004): 565-595.

4. Ibid. $\hookleftarrow$

5. David Harvey, Social Justice and the City (Atlanta: University of Georgia Press, 2009); Doreen Massey, Spatial Divisions of Labour: Social Structures and the Geography of Production (New York: Methuen, 1984); Jonathan Murdoch, Post-Structuralist Geography: A Guide to Relational Space (Thousand Oaks, CA: Sage Publications Ltd, 2006).

6. Anthony C. Gatrell, Distance and Space: A Geographical Perspective, Contemporary Problems in Geography (Oxford (Oxfordshire) : New York: Clarendon Press; Oxford University Press, 1983); Trevor J. Barnes, “'Not Only ... But Also': Quantitative and Critical Geography," The Professional Geographer 61, no. 3 (July 6, 2009): 292-300, doi:10.1080/00330120902931937; Luke Bergmann, Eric Sheppard, and Paul S Plummer, "Capitalism beyond Harmonious Equilibrium: Mathematics as If Human Agency Mattered," Environment and Planning A 41, no. 2 (2009): 265-83, doi:10.1068/a411.

7. Craig M Dalton, Linnet Taylor, and Jim Thatcher. "Critical Data Studies: A Dialog on Data and Space." Big Data \& Society 3, no. 1. (January 5, 2016): 205395171664834. https://doi.org/10.1177/2053951716648346.

8. John Pickles, ed., Ground Truth: The Social Implications of Geographic Information Systems, Mappings (New York: Guilford Press, 1995), 3.

9. Taylor, 1990 (pg. 211).

10. Nadine Schuurman, "Trouble in the Heartland: GIS and Its Critics in the 1990s," Progress in Human Geography 24, no. 4 (December 1, 2000): 569-90, https://doi.org/10.1191/030913200100189111.

11. Francis Harvey, Mei-Po Kwan, and Marianna Pavlovskaya, "Introduction: Critical GIS." Cartographica 40, no. 4 (2005): 1-4; Nadine 
Schuurman and Geraldine Pratt, "Care of the Subject: Feminism and Critiques of GIS." Gender, Place \& Culture: A Journal of Feminist Geography 9, no. 3 (2002): 291-99.

12. James Ash, Rob Kitchin, and Agnieszka Leszczynski, "Digital Turn, Digital Geographies?," Progress in Human Geography, August 24, 2016, https://doi.org/10.1177/0309132516664800.

13. Ryan Burns, "Rethinking Big Data in Digital Humanitarianism: Practices, Epistemologies, and Social Relations." GeoJournal 80, no. 4 (2015): 477-90; Sarah Elwood, "Geographic Information Science: Emerging Research on the Societal Implications of the Geospatial Web." Progress in Human Geography 34, no. 3 (2010): 349-57; Rob Kitchin, Martin Dodge, and Matthew Zook, "Guest Editorial: How Does Software Make Space? Exploring Some Geographical Dimensions of Pervasive Computing and Software Studies." Environment and Planning 41 (2009): 1283-93.

14. Ryan Burns and André Skupin, "Towards Qualitative Geovisual Analytics: A Case Study Involving Places, People, and Mediated Experience." Cartographia 48, no. 3 (2013): 157-176; Meghan Cope and Sarah Elwood, eds., Qualitative GIS: A Mixed Methods Approach; (Thousand Oaks, CA: Sage Publications, 2009); Jin-Kyu Jung and Sarah Elwood, "Extending the Qualitative Capabilities of GIS: Computer-Aided Qualitative GIS."Transactions in GIS 14, no. 1 (2010): 63-87.

15. See Node.js (https://nodejs.org/en/) as an example of Javascript-based operating systems and Jason Davies' collection of Javascript-based spatial data visualizations here: https://www.jasondavies.com/

16. As seen in new journals like GeoHumanities and Big Data \& Society, and more longstanding journals such as New Media \& Society. $\hookleftarrow$

17. Scott Kirsch, "The Incredible Shrinking World? Technology and the Production of Space," Environment and Planning D: Society and Space 13, no. 5 (1995): 529-55, https://doi.org/10.1068/d130529.

18. Doreen Massey, "Power-Geometry and a Progressive Sense of Place," in Mapping the Futures, ed. Jon Bird et al. (London ; New York: Routledge, 1993).

19. Nigel Thrift and Shaun French, "The Automatic Production of Space," Transactions of the Institute of British Geographers 27, no. 3 (September 2002): 309-35, https://doi.org/10.1111/1475-5661.00057.

20. Paul Dourish and Genevieve Bell, "The Infrastructure of Experience and the Experience of Infrastructure: Meaning and Structure in Everyday Encounters with Space," Environment and Planning B: Planning and Design 34, no. 3 (2007): 417, https://doi.org/10.1068/b32035t.

21. Shannon Mattern, "History of the Urban Dashboard," Places Journal, 2015, https://placesjournal.org/article/mission-control-ahistory-of-the-urban-dashboard/. $\hookleftarrow$

22. Derek Gregory, Geographical Imaginations (Cambridge, MA: Blackwell, 1994).

23. Rob Kitchin and Martin Dodge, Code/Space: Software and Everyday Life, Software Studies (Cambridge, Mass: MIT Press, 2011). $\hookleftarrow$

24. Martin Dodge, and Rob Kitchin, "Flying through Code/Space: The Real Virtuality of Air Travel." Environment and Planning A; 36 , no. 2 (2004): 195-212; Dodge and Kitchin 2004; Kitchin, Dodge, and Zook, "How Does Software Make Space"; Mark Graham, "Neogeography and the Palimpsests of Place: Web 2.0 and the Construction of a Virtual Earth." Tijdschrift Voor Economische En Sociale Geografie 101, no. 4 (2010): 422-36.

25. Stephen DN Graham, "Software-Sorted Geographies," Progress in Human Geography 29, no. 5 (2005): 562-580.

26. Matthew W Wilson, "Continuous Connectivity, Handheld Computers, and Mobile Spatial Knowledge," Environment and Planning D: Society and Space 32, no. 3 (2014): 535-55, https://doi.org/10.1068/d14112.

27. Benjamin H. Bratton, The Stack: On Software and Sovereignty, Software Studies (Cambridge, Massachusetts: MIT Press, 2015). $\hookleftarrow$

28. Shannon Mattern, "Cloud and Field- On the Resurgence of 'Field Guides' in a Networked Age" (Places Journal, 2016), https://doi.org/10.22269/160802.

29. Louise Amoore, "Data Derivatives: On the Emergence of a Security Risk Calculus for Our Times." Theory, Culture \& Society 28 , no. 6 (2011): 24-43; Mei-Po Kwan, "Algorithmic Geographies: Big Data, Algorithmic Uncertainty, and the Production of Geographic Knowledge." Annals of the American Association of Geographers 106, no. 2 (March 3, 2016): 274-82; Jeremy Crampton, and Andrea Miller, "Intervention Symposium: 'Algorithmic Governance.'” Antipode Foundation (blog) , May 19, 2017, https://antipodefoundation.org/2017/05/19/algorithmic-governance/. $\hookleftarrow$

30. Jennifer Gabrys, "Programming Environments: Environmentality and Citizen Sensing in the Smart City.: In Smart Urbanism: Utopian Vision or False Dawn? , edited by Simon Marvin, Andrés Luque-Ayala, and Colin McFarlane, 88-107 (New York: Routledge, 2016).

31. Alexander Galloway, Protocol: How Control Exists after Decentralization (Cambridge, MA: MIT Press, 2004); Michael Crang, and Stephen Graham, "Sentient Cities: Ambient Intelligence and the Politics of Urban Space." Information, Communication \& Society 10, no. 6 (2007): 789-817; Rob Kitchin, and Martin Dodge, Code/Space: Software and Everyday Life (Cambridge, MA: MIT Press, 2012); Sam Kinsley, "The Matter of 'Virtual' Geographies." Progress in Human Geography 38, no. 3 (2014): 364-84; Keith Woodward, John Paul Jones, Linda Vigdor, Sallie Marston, Harriet Hawkins, and Deborah Dixon, "One Sinister Hurricane: Simondon and Collaborative Visualization." Annals of the Association of American Geographers 105, no. 3 (2015): 496-511.

32. Adrian Mackenzie, Transductions: Bodies and Machines at Speed (London: Continuum Press, 2002).

33. Ryan Burns, "Moments of Closure in the Knowledge Politics of Digital Humanitarianism." Geoforum 53 (2014): 51-62; Keith Woodward, John Paul Jones, Linda Vigdor, Sallie Marston, Harriet Hawkins, and Deborah Dixon, "One Sinister Hurricane: Simondon and Collaborative Visualization." Annals of the Association of American Geographers 105, no. 3 (2015): 496-511. $\hookleftarrow$

34. Gillian Rose, "Posthuman Agency in the Digitally Mediated City: Exteriorization, Individuation, Reinvention." Annals of the American Association of Geographers 107, no. 4 (2017): 779-93.

35. Bernard Stiegler, Technics and Time, 1: The Fault of Epimetheus. Translated by Richard Beardsworth and George Collins (Stanford, CA: Stanford University Press, 1998). $\hookleftarrow$

36. Patrick Meier, "Crisis Mapping in Action: How Open Source Software and Global Volunteer Networks Are Changing the World, One Map at a Time." Journal of Map \& Geography Libraries: Advances in Geospatial Information, Collections \& Archives 8, no. 2 (2012), 90; Patrick Meier, Digital Humanitarians: How Big Data Is Changing the Face of Humanitarian Response (Boca Raton, FL: CRC Press, 2015), 198.

37. Burns, "Moments of Closure".

38. Michal Givoni, "Between Micro Mappers and Missing Maps: Digital Humanitarianism and the Politics of Material Participation in Disaster Response.” Environment and Planning D: Society and Space; 34, no. 6 (December 1, 2016), 1029.

39. Mark Duffield, "The Resilience of the Ruins: Towards a Critique of Digital Humanitarianism." Resilience;, 2016, 147-65.

40. Ryan Burns, "Let the Private Sector Take Care of This': The Philanthro-Capitalism of Digital Humanitarianism." In Digital Economies at the Global Margins, edited by Mark Graham (Cambridge, MA: MIT Press, forthcoming).

41. See Bratton (2016) for the most prominent engagement with the concept of the stack.

42. T. Straube, "Stacked Spaces: Mapping Digital Infrastructures," Big Data \& Society 3, no. 2 (September 19, 2016), 
https://doi.org/10.1177/2053951716642456.

43. For a manuscript of this talk, see Laura Beltz-Imaoka, "Selling the Conceptual and Computational Value of Esri's ArcGIS Platform." SocArXiv, July 2, 2017. https://osf.io/preprints/socarxiv/tzewh. ↔

44. For a more detailed description of this study, see Matthias Plennart, "Anwendungsreif? Nutzung und Potenzial von digitalen Geodaten für Stadtforschung und Raumbeobachtung am Fallbeispiel OpenStreetMap." Social Science Open Access Repository, 2016. http://www.ssoar.info/ssoar/handle/document/50501.

45. See Burns, "Moments of Closure", for a discussion of these knowledge politics, and the "moments of closure" that delimit and frame knowledge production.

46. See Luke Bergmann, "Toward Speculative Data: 'Geographic Information' for Situated Knowledges, Vibrant Matter, and Relational Spaces." Environment and Planning D: Society and Space 34, no. 6 (2016): 971-89. https://doi.org/10.1177/0263775816665118. $\hookleftarrow$

47. Luke Bergmann, and David O'Sullivan, "Reimagining GIScience for Relational Spaces." The Canadian Geographer / Le Géographe Canadien, 2017, 1-8. https://doi.org/10.1111/cag.12405; Luke R. Bergmann and Nick Lally, "For geographical imagination systems (GIS)." In Preparation

48. See also, Craig Dalton, "Big Data from the Ground Up: Mobile Maps and Geographic Knowledge." The Professional Geographer, June 20, 2017, 1-8. https://doi.org/10.1080/00330124.2017.1326085.

49. A published version of this talk can be found at Aaron Shapiro, "Street-Level: Google Street View's Abstraction by Datafication." New Media \& Society, 2017, 1461444816687293. https://doi.org/10.1177/1461444816687293.

50. See also Teresa Scassa, "Legal Issues with Volunteered Geographic Information." The Canadian Geographer / Le Géographe Canadien\&/t 57, no. 1 (March 1, 2013): 1-10. https://doi.org/10.1111/j.1541-0064.2012.00444.x.

51. See Gillian Rose, Monica Degen, and Clare Melhuish, "Networks, Interfaces, and Computer-Generated Images: Learning from Digital Visualizations of Urban Redevelopment Projects." Environment \& Planning D 32, no. 3 (2014): 386-403.

52. See Woodward et al, "One Sinister Hurricane." $\hookleftarrow$

53. See Alan Wiig, and Elvin Wyly, "Introduction: Thinking through the Politics of the Smart City." Urban Geography 37, no. 4 (2016): 485-93. https://doi.org/10.1080/02723638.2016.1178479.

54. See Thornton, this issue; and for other works, Pip Thornton, "The Meaning of Light: Seeing and Being on the Battlefield." Cultural Geographies 22, no. 4 (2015): 567-583.

55. See Daniel Cockayne, and Lizzie Richardson, "Queering Code/Space: The Co-Production of Socio-Sexual Codes and Digital Technologies." Gender, Place \& Culture, June 12, 2017, 1-17. https://doi.org/10.1080/0966369X.2017.1339672.

56. See Matthew W Wilson, New Lines: Critical GIS and the Trouble of the Map. Minneapolis, MN: University Of Minnesota Press, 2017. $\hookleftarrow$

57. In using this term, geographers are typically referring to the work of Henri Lefebvre (1991), who constructed a tripartite conceptualization of space: lived space, representations of space, and representational space. $\hookleftarrow$

58. This term was coined and clarified by Doreen Massey (1994) as a nexus of spatial relations that come to bear upon phenomena such as individuals, the state, knowledge, and political-economies. $\hookleftarrow$

59. Barnes, "Placing Ideas."

60. Schuurman, "Trouble in the Heartland."

- Series Navigation

$<<$ Welcome to the Polygon: Contested Digital Neighborhoods and Spatialized Segregation on NextdoorDance Becoming Data:

Part One Software for Dancers >> 